\title{
BROAD VALLEYS OF THE CORDILLERAS
}

BY N. S. SHALER

(Presented before the Society December 29, 1900)

\section{CONTENTS}

Introduction $\ldots \ldots \ldots \ldots \ldots \ldots \ldots \ldots \ldots \ldots \ldots \ldots \ldots \ldots \ldots \ldots \ldots \ldots \ldots \ldots \ldots$

State of the valleys........................................ 272

Structure of the valley deposits.............................. 274

Method of infilling of the broad valleys......................... 282

Effects of deposition......................................... 294

Exceptional valleys....................................... 297

Possible cause of increased raiufall in eastern Cordilleras............... 299

Conclusions ............................................. 300

\section{IN'TRODUCTION}

In the following pages I propose to set forth the results of observations made in that part of the Cordilleran system which lies within the limits of the United States, excluding Alaska. The main end in view is to exhibit the history of the erosive processes in that region with reference to successive changes in climate during the later geological periods. Incidentally, reference will be made to the general conditions of erosion in mountainous countries and to the effects of alternating plentiful and scanty rainfall on the forms of valleys as well as the influence of the volcanic ejections which have occurred in the Cordilleras since the existing topography began to be developed.

Although the results of the inquiries which are recorded below represent a considerable amount of labor, including journeys aggregating a distance of more than 10,000 miles within the area above noted, they must be regarded as in a great measure tentative. The field of the inquiry is large and, while the facts set forth are tolerably clear, the conclusions to be drawn from them are open to debate. It is, moreover, evident that the matter deserves a more extended study. This paper undertakes little more than to indicate in general the value of the 
results which may in time be attained by following certain series of phenomena exhibited in the valleys of the Cordilleran district.

\section{State of the Valleys}

It has often been observed that the valleys of the larger streams in many parts of the Cordilleras-at least within the limits of the United States-are prevailingly of remarkable width, their aspect being often that of broad plains, sloping gently from the bases of the mountains on either side to the rivers which drain them. These streams are usually without definite banks and not directly controlled, as regards their positions, by the bed rocks of the mountain ranges. Here and there, though exceptionally, this great area exhibits streams which have carved very deep canyons-a ty pe of valleys in singular contrast to the more common broad vales. There is no definite series connecting these deeply carved, narrow valleys with those of the broad form. The two groups are, indeed, sharply contrasted; the variety of intermediate forms seems to indicate some essential difference in their histories.

The valleys of the broad type are formed of two very distinct topographical elements-the mountain walls on either side and the slopeslocally termed "benches," which extend, with gentle declivities, from the base of their steeps to the central part of the trough. The mountains

exhibit the usual range in form, their torrent valleys above the zone of gentle slopes having the normal shapes due to the incising action of swift-flowing streams. Except that the gently sloping surfaces characteristic of the broad vales often penetrate for some miles upward into the troughs of these lesser streams, they in no noticeable way differ from those similarly placed in other elevated districts. Passing from the steep, mountainous country into the vale, there is commonly an abrupt change in the angle of the slopes. They decline to an average of probably less than 100 feet to the mile. Although this slope is often quite uniform for the distance-it may be of several miles-there is commonly a rather gradual decline in the grade, so that it passes from about 2 feet in 100 next the rocky borders to less than one-half foot in that distance in the central part of the vale. The surface of these sloping bottoms of the broad valleys is little varied, except where they are intersected by the greater streams which make their way across them from the torren $t$ zone to the main water-courses. At these points the benches are traversed by valleys, usually of considerable width, which are occupied by local deposits evidently of detrital origin and of lesser declivity than those they intersect as well as of more recent formation.

Although in most instances the valleys we are considering are un- 
broken by isolated eminences of a mountainous nature, it not infrequently happens that low peaks protrude above the generally even surface and occasionally a considerable mountain range breaks their slopes. Here and there, especially when the valleys are of the widest form, volcanic peaks occur, commonly as degraded stocks-that is, the remnants of cones. In fact these structures, though not common, are among the characteristic features of these broad vales They are irregularly distributed, sometimes lying in the central part of the troughs; again, perhaps most commonly, near their borders or even in the marginal parts of the mountain ranges that constitute the divides between the drainage basins.

Noting the evident likeness of these broad valleys to those of rivers in a country brought near to its baselevel of erosion, the observer is at first led to the supposition that they are but extreme instances of widened drainage troughs, wherein, as usual, the cutting streams in their windings have excavated very wide vales. A little observation shows that this explanation is insufficient for the reason that nowhere are the watercourses now at work on the hard bed rocks of the country, access to them being made impossible by the long detrital slopes on either side. These slopes, though they are made of rather incoherent detritus, are never cut into escarpments of any considerable height. They control the drainage and are not controlled by it. Finding, as we do, many instances of valleys 10 miles or more in width and 50 or more in length, with their rivers everywhere defended by detritus from their ordinary incising work, we are forced to conclude that these vales are not widening by the swingings of their drainage channels and the successive excavations which are thus induced.

The next working hypothesis which may be adduced is that these broad valleys, after having been excavated to a much greater depth than they now exhibit, have, by some process of warping or tilting of the region in which they lie, been converted into lakes, and that their sloping central parts are made up of lacustrine deposits. That such is not generally the case is indicated, as will be shown further on, by the character of the deposits, but even more clearly by the topographic shape of the materials. Save in such instances as are afforded by the extinct lakes of the Bonneville group, where there are characteristic shorelines, the lacustrine hypothesis, though frequently applied, is usually inadmissible. This is indicated by the facts now to be set forth.

Where we trace the margins of the slopes or benches to their contact with the bordering ranges we nowhere find distinct beach terraces such as are so well exhibited about the Utah lakes. It can not be assumed that such terraces once existed, but have been destroyed, for such ruining action would have greatly changed the surface of the slopes, which 
still extend in admirable continuity up to the foot of the rocky steeps. Moreover, if we follow up the lines of contact of the slopes with the ranges toward the head of any of the main branches of a river system such as that of the Missouri, we find that these lines rise, though it may be at a less rate, with the general ascent of the valleys. To suppose that the margins of the slopes marked, even in a general way, the shores of extinct lakes would require an hypothesis of secondary tilting for each valley such as would be quite inadmissible. Thus, while here and there lacustrine deposition has undoubtedly played some part in the development of the existing forms of these troughs, it can not be held that the process has been the main agent in giving them their shape. Further reasons for dismissing this hypothesis appear when we examine into the constitution of the deposits which underlie the approximately level parts of these valleys.

\section{Structure of the Valley Deposits}

Owing to the fact that the streams which drain the valleys of the broad type do not, to any considerable extent, attack the deposits by which they flow, there are very few natural sections of value to the observer. The surface of the beds is, in most parts of the field, covered with a soil in which more or less angular pebbles abound. At many points the burrowing insects and mammals have brought the finer debris which originally lay between the pebbles within a few feet of the top to the surface, so that it has been blown away by the wind. By the growth of vegetation, a part of the decomposed rock has been brought to the air, where, after the decay of the plants, it is likewise thus swept off. 'The result of these deportative actions has been to so far concentrate the pebbly material of the soil that in the more arid portions of the Cordilleras the ground is often completely covered with coarse fragments. Where quantities of earthy matter have thus been removed in the form of dust it is common to find considerable deposits of the wind-blown material along the banks of the streams having a thickness of from 3 to 6 feet. The deposition takes place because the speed of the wind is lessened in the tangle of vegetation which grows in the humid belt near the streams. A portion of this blown debris finds its way up into the mountains, where it comes temporarily to rest in the forests and grassed fields. Much of it appears to journey on in the prevailing westerly winds until it passes beyond the eastern border of the mountain system.

Penetrating beneath the concentration of debris produced in the manner above noted, we find in the ordinary limited sections such as are afforded by railway cuttings and irrigation ditches or the occasional shaft 
wells concerning which information can be had, the subjacent beds commonly made up of fragmental materials in general as appears at the surface. The pebbles in these beds are usually not much water-worn, except where they have evidently been transported from a considerable distance by the mountain torrents and accumulated on their detrital areas. In such positions they have the character common to such pebbles. In all the instances where I have been able to identify the source of these fragments they have come from the rocks of the neighboring mountains. Although the observations I have made are limited, they go to show that the proportion of materials coarse enough to be termed pebbly is large, commonly more than three-fourths of the mass, and that these pebbles are much decayed.

As regards the size and distribution of the fragments, they are clearly larger the nearer they are to the bases of the mountain walls. There is, indeed, a tolerably uniform decrease in their size as they lie farther away from the highest part of the slopes; yet it is not uncommon to find fragments as much as a foot in diameter at a distance of 2 or 3 miles from the source whence they came. The extent to which they are decayed usually increases as they lie farther out toward the center of the valley. Where the rocks are granitic and of a rather perishable character, as about the Silver Bow river, near Butte, Montana, the coarse element in the deposit does not commonly extend for any considerable distance from the foot of the mountains. In these conditions the material of the slopes ordinarily consists of the disintegrated rock of which the crystals are sufficiently well preserved to warrant the term arkose being applied to the mass. The formation of these peculiar beds is greatly favored, if, indeed, it is not mainly brought about, by certain species of ants which abound in nearly all parts of the Cordilleras. These creatures accumulate upon their hills quantities of the fragments which have become loosened by the decay of the crystalline rocks. It is not uncommon to find in one of their heaps as much as 2 or 3 cubic feet of such debris. At several places, particularly in A rizona, I have noted, over large areas, as many as 50 of these hills to the acre of ground, with the result that in a single square mile there may be several hundred cubic yards of material ready to be swept away by a torrential rain, to be laid down in the lower parts of the valley.

It may be incidentally noted that one of these species of ants which particularly abounds in the southern part of the Cordilleras has another habit which facilitates soil erosion both by rain and wind. This insect completely removes the grass and other lowly vegetation over a circle from 10 to 20 feet in diameter, in the center of which lies the nest or hill. As the roots of the plants are extirpated the ground is deprived of its 
natural protection, and, as the circles in question are often so distributed that their margins are almost in contact, the result is that the sheets of water which flow over the ground when a torrential rain, the so-called "cloud-burst," occurs are likely to find the earth quite without its natural protection against erosion.

The only place where I have been able to make any satisfactory observations as to the structure of the deposits of the detrital slopes of the valleys at a depth of more than 30 feet below the surface is in the region about Butte, Montana. At that point a number of shafts have been sunk through the debris which fills the valley of the Silver Bow river. 'These shafts are all abandoned, so that the only information concerning them has been derived from the waste about the pit mouths and from the statements of those who remember something of what was encountered in the work of sinking them. It seems tolerably certain that the deepest of those shafts sunk near the center of the valley slopes, which are here about 2 miles wide, failed to attain the bed rock at a depth of between 3 and 4 hundred feet, and that the material passed through was principally of a nature approximating to arkose, with occasional pebbles composed of the harder dikes which intersect the crystalline rocks of the country. At other points in the valleys of the Upper Missouri system, especially in that of the Stinking Water, now renamed the Ruby, borings which I had a chance to observe indicated that the material to a depth of 50 feet and at a distance of about 4 miles from the Old Baldy section of the 'Tobacco Root range contained coarse pebbles. Various railway and irrigation ditch sections from northern Montana to central Arizona clearly show that this pebbly nature is common to the deposit.

At some points this detritus forming the benches of the valley, when it is of an arkose nature, has become cemented in so firm a manner that it is readily mistaken for granite. In two instances I have known this mistake made by competent mining experts, who were not to be persuaded of their error until they were shown that ordinary gravel lay beneath the firm beds. 'These recomposed crystalline rocks appear in all cases to occur near the foot of the mountains in places where the grains of decayed granitic rocks have not been much rounded or deprived of that part of their matter which was readily soluble.

So far as the inadequate sections give information concerning the materials underlying the general surface of the valley, they indicate, as before noted, that the deposits consist of debris brought from the adjacent mountains. 'This mixture of clay, sand, pebbles, and larger fragments is rudely stratified; the bedding is irregular and often scarcely traceable, but has an evident dip toward the center of the valley in which the deposit 
lies. Very often we find a mass of ordinary torrent waste intercalated in the body of less transported material. These accumulations sometimes occur where they can not be certainly referred to any neighboring torrent valley, yet they clearly are the product of some mountain stream which has shifted its position since the pebbles were laid down. In the depressions of the slopes through which the mountain streams pass on their way to the main rivers I have found, notably in the valley' of the Ruby river of Montana, a class of materials in marked contrast with those which make up the unconsolidated beds of the main valleys. Thus in pits sunk to test the value of auriferous gravels at Alder creek, in Madison county, Montana, the deposits of a pebbly nature constituting the detrital cone of the stream which lies in a wide depression of the principal slope of the vale have a thickness of from 20 to 60 feet, their depth increasing toward the center of the valley. Beneath this pebbly bed, with a very sharp transition, we come upon a grayish white clayey deposit of an absolutely homogeneous character, which has been bored through to the depth of 90 feet without finding bottom. This clay-like matter continues upward in the flat-bottomed gulch occupied by Alder creek for about 5 miles from the mouth of the canyon; at 3 miles above that point it has a thickness of over 100 feet.

Although occasional fossils are found in the torrent gravels which have been formed since the Glacial period, they give no trustworthy evidence as to the age of the deposits. I have gathered from Alder gulch, within the upper limits of the detrital cone, near to or upon the foundation of volcanic ash before referred to, several disjointed fragments of the skeleton of an elephant and teeth of Elephas primigenius, but in the same section have found a part of the jaw of a morosaurus. As there are evidently no Cretaceous beds now existing in the valley of that creek, we may presume that this latter fossil came from deposits that have been completely removed from the district. So far as I am aware, no fossils have been found in the probably more ancient taluses of the broad valleys.

As yet the nature and origin of the Alder Gulch clay is somewhat uncertain. The components of the mass are so far decayed that they can not be clearly identified. 'The facts, however, warrant the supposition that the mass was derived from a basic, volcanic ash. These facts are as follows: The clay is quite unmixed with pebbles or even distinct grains of sand; it is not even stained with iron as an ordinary sedimentary clay made in such a position would be. It exhibits no distinct stratification. It does not become coarser on approaching the mountain or even in the upper parts of the canyon of Alder creek. Moreover, on the westerly side of that stream, near the mouth of Granite creek, it is immediately overlaid by lava flows which have certainly at 
one time overspread all of the valley of that stream. Not only on either side of the channel lie the dissected fragments of an extensive mesa of basalt, but there are the stocks of minor cones within a radius of 5 miles which were evidently in eruption long after the older clay-like material had been much dissected by the torrents that traverse it. These conditions make it reasonable to suppose that the clays above referred to have been derived from the decomposition of volcanic ash accumulated when it fell or washed into position by the rains which commonly attend eruptions.

It appears clear that these ash beds were accumulated during a volcanic outbreak which followed the construction of the main benches of the valley. They evidently do not extend beneath the general surface of the benches at least in those parts of the area adjacent to the mountains, though they are probably to be found in the central part of the troughs. The deposit which lies beneath Alder creek has been traced by borings almost out to Ruby river, a distance of 3 miles from the mountain walls. On either side it appears to come into contact with, but not to pass under, the material of the benches. It thus appears likely that the ash must have been laid down on the general surface of the country and afterward swept into the channel of the creek. It is certain that none of it is now visible on the levels above the stream bed, and that it is covered by a thick layer of debris comprised of the rocks which make up the mass of the neighboring mountains.

The fact that at Alder creek the rock channel has been so deeply filled that at 7 miles up from its junction with Ruby river its present level is over 100 feet above its original bed, and that an even deeper infilling has taken place in the Silver Bow valley near the head of a small branch of the river, shows clearly that very great chunges have taken place in relatively modern times in the details of the form of the valleys of the Upper Missouri district. I now propose to consider what are the real shapes of these vales beneath the masses of detritus with which they have become thus occluded. I have already noted the fact that the valley deposits, from the lack of natural sections, most effectively mask the shape of the bed-rock outlines. At only one point, namely, in the city of Butte, have I been able to find any artificial cuts through the upper parts of the slopes that reach the bed rock. In that town, however, many openings, especially those for a system of sewerage, have disclosed facts of much interest, which, taken with other bits of information, enable us to construct a tolerable picture at least locally true of the hidden bed-rock floors of these troughs.

It is first to be noted that the detrital slope on which the city of Butte is built extends from near the top of a degraded mountain to Silver Bow 
creek, a distance of about 2 miles. In the angle of its declivity, its general form, and the character of the material next the surface it is essentially like the other benches of the Cordilleran valley. It has the normal width of these slope benches in valleys occupied by streams of like volume. I Jeft in its undisturbed state, it would have been classed with the other like structures. The only peculiar feature is found in the more than usual readiness with which the granitic and volcanic rocks of the ridge decay. These rocks disintegrate at a considerably greater rate than the average of the mountain-building formations of the area, with the result that the Butte ridge has evidently lost in height more rapidly than the other divides of this region. The only effect of these local conditions has been to hasten the processes by which the valley was formed, so that the trough is somewhat broader than it would otherwise have been.

The plentiful openings which have been made in the talus slopes beneath Butte show that the bed rocks form a tolerably continuous incline in which there are no conspicuous departures from a regularly inclined surface to a line about 1,000 feet from the gereral position of Silver Bow creek; there they turn rather suddenly downward. On the opposite side of the stream toward the now bald granitic hill known as Timber butte the few pits that have been sunk indicate a similar position of the bed rocks. The gorge into which these slopes of the firm rocks decline. apparently has a width of one-half mile. Its depth is uncertain, but as it is clearly at least 400 feet deep in the small branch of the creek that lies to the east of the town between it and the Coutinental divide, we may assume a considerably greater depth of the buried gorge on the line of this crosssection above mentioned. Assuming that this buried canyon has the slope of the walls continued downward in the form of a $\mathrm{V}$ and with the steepness they have near their margin, it is likely that the bed of the ancient stream is at least 600 feet below the present course of its waters.

A careful inspection of the Silver Bow valley from the canyon on the west to the head of the streams that drain it warrants the supposition that the same form of the bed rocks exists in all its parts. Everywhere the numerous prospect holes made in the search for ore-bearing veins reveal the presence of the crystallines beneath from 5 to 50 feet of surface debris out to a line from 1 to 2 miles beyond the mountain steeps, and then a swift descent of the under rocks to a narrow and deep channel. As to the nature of the filling of this deep gorge we have no certain information. It is said, however, that wells near the stream have encountered a whitish clay at the depth of 30 feet which may be of volcanic origin. Assuming that the valley of the Silver Bow has been thus deeply excavated and refilled, the question arises whether this cavity 
could have been produced by other than river action. For reasons already given it seems impossible that these channels should have been formed by differential warping, for if such were the case the movement would have had to follow the paths of the much-branched valley; moreover, the form of the central gorges of these troughs is altogether inconsistent with the supposition that they are due to such movements. We have thus to believe that the stream beds of this area were, at no geologically distant date, several hundred, perhaps a thousand, feet lower than they are at present.

The passage from the broad valley of the upper Silver Bow to the narrow gorge by which the waters of the basin find their exit clearly demands explanation. This may possibly be found in the fact that the rocks through which this channel is cut evidently decay rather slowly, and so developed a narrow canyon gorge. It is, however, not unlikely that there has been here, as elsewhere in the Cordilleras, a recent change in the path of escape of the stream by which a new way of escape was provided, so that the higher portion of the vale was formed or at least outlined with one baselevel of drainage, and the lower at another such level. This is, however, a question of detail that cannot well be here considered.

In the part of the Ruby River valley near Alder creek the evidence obtained from borings, as before noted, together with that gained by an inspection of the surface features of that area, shows conditions of the ancient topography substantially the same as those found near Butte. The sloping platform of the ancient rocks on the northern side of the vale is evidently continued out for an unknown distance toward the center of the valley. Through it Alder Creek canyon extends with an unknown depth. The same appears to be the case with other similar lateral gorges. At various other points in the broad valleys of the Upper Missouri River system chance excavations show a like extension of the slope of bed-rock for some distance out from the mountains toward the streams. None of these sections afford any clear indication of the depth of the central trough, but in all of the instances observed the rate of the decline is so great that the depth in the middle of the trough must be profound.

The above-noted very limited observations as to the under form of the Cordilleran broad valleys are of themselves clearly insufficient to warrant any general conclusions as to the existence of a like topography in other parts of the region. There are, however, certain groups of facts which enable us, with qualifications to be noted, to extend the conclusions, with varying certainty, over the whole of this field. First let us note that the valleys in question, though the walls of their mountain 
borders are remarkably straight, not infrequently have outliers which lie a little way removed toward the centers of the troughs. These are of the harder rocks, such as are found in a region of varied structure. It is a noticeable fact that scarcely any of these isolated masses occur far out from the main ranges. Very seldom in valleys 10 miles in width do they appear at more than a mile from the upper margin of the valley slopes. Now, it may be assumed that in any normal process of valley erosion producing basins 10 to 20 miles in width there must have been many outlying eminences left on its floor, of which the summits would have remained at a relatively great height above the bottom of the excavation. We should, for instance, in vales such as these were before they were in large part filled, expect to find, even near their central parts, outlying elevations some thousands of feet in height above the level of the drainage channel. As above remarked, except along the margins of these wide expanses, we do not find any trace of these normal remainders of erosion where it acts on rocks of diverse resistance, such as are found in almost all parts of the region we are considering. These topographic outliers may be seen in all conditions of occlusion by the valley beds, from the state in which the rocks connecting them with the main ranges are still uncovered to that where only the very tips of the summits break the surface of the detrital slopes. Although this kind of evidence clearly indicates the very great original depth of these valleys before the process of obstruction began, it does not afford any sufficient basis on which to reckon their original depth in terms of feet or even in miles. A study of the facts in the field, however, brings the observer to the hypothesis that in the average of these vales-as, for instance, that of the Jefferson or Gallatin river-the amount of the infilling must amount to not less than 5,000 feet.

The evidence goes to show that the erosion of the valleys of the Rocky mountans was accomplished with exceptional rapidity. This is well indicated by the fact that the remains of ancient river channels, now filled with gravels, lie at a remarkable height above the present levels of the main streams. Thus, on the mountain known as "Old Baldy," in Madison county, Montana, there are the fragments of several deep troughs, which were originally the seat of large mountain torrents, which are filled with river gravels to the depth of over 200 feet. These gravels are of so recent an aspect that they have been mapped on the United States Geological Survey sheets as glacial drift, a mistake which was most natural for the reason that it is only recently that extensive excavations, in searching for placer gold, have revealed their true character. The unmetamorphosed condition of these gravels makes it seem likely that they are of no older than Tertiary age; yet since they were deposited 
the Madison and the Ruby rivers, at the base of the mountain, have cut down 3,000 feet to the present level of these streams, and also for the unknown depth of the troughs that lie below the detritus that partly fills the valleys. The total erosion can not well be less than 6,000 feet and may very much exceed that estimate, yet it has apparently been accomplished in geologically modern times, certainly since the Cretaceous period. This instance of high lying, apparently recent gravels is but one of many that could be cited from the region about the headwaters of the Missouri. They occur at a number of points about the Madison river and elsewhere.

Although we have to estimate the original depth of the valleys as surprisingly great, the estimate does not have to go so far as it would if we were to neglect the broad shoulders or bed-rock slopes which, we have reason, as at Butte, to suppose, commonly lie beneath the lateral parts of the detrital accumulations. If we should suppose the declivities of one of the broader of these troughs to be carried downward as continuous slopes to the center of the excavation, we would have to reckon an almost impossibly strong topography. On this basis we should have valleys equal to, if not exceeding, any now existing on this sphere. As it is, we cannot well escape the conclusion that some of these vales have the sites of their original streams below the level of the sea; that if the debris that now fills them were removed they would have more than twice their existing depth.

An evident objection to the supposition that these valleys once had the great depth which is here assigned to them is found in the fact that the streams which drain them sometimes pass over bed rocks at a level which is not far from the present beds of the streams that traverse them. Thus the Missouri at Great Falls flows on the bed rock, and like conditions may be found elsewhere. In answer to this objection it may be said that these valleys are evidently very ancient, and that extensive local warpings have clearly taken place since they were formed. Moreover, in such instances as that of the falls of the Missouri it is possible that the stream has been so far displaced by the infilling of its original channel as to flow at some distance from the path it followed when the channels were excavated.

\section{Method of Infilling of 'HHe BRoAd Valleys}

We have now to consider the conditions which have led to the deposition of the beds that have so far occluded the greater part of the Cordilleran valleys within the limits of the United States. Incidentally we have noted that these accumulations were not to any considerable ex- 
tent formed in lakes. There are, however, various possible explanations of the infilling action which need to be examined. In approaching the inquiry it is well to see clearly that the main question is as to the ways in which the detritus swept from the fields of erosion in the mountain ranges has come to be retained in the valleys near its sources, or, in other words, how the disturbance in the normal balance between the agents which serve to break up rock materials and start them downward and those which provide for their distant transportation has been disturbed. It is evident that while these valleys were in process of excavation the rivers were competent to carry away all the debris that came to them, and that for a long time they have been unable to effect this work. The question is as to what has brought about this change.

There are several diverse influences which may serve to diminish the capacity of streams for carrying detritus to the sea. These may be stated as follows: First, the surface over which they flow may be so far lowered that the grades from the base line upward may be'too slight to give the rivers the speed required for carrying the amount of debris that is brought down to them by the torrents; second, by a differential movement of the lands the valleys may be so tilted that their outlets are disturbed and their exit grades diminished; third, by change in the adjustments of the rainfall and of the atmospheric decay of the rocks, which goes far to determine its erosive value, the amount of material brought down from the heights into the valleys may much exceed that which the streams can bear away to the lower country or to the sea, and the state of this eroded material may be such that it is not readily moved by the rivers.

As for the first of the working hypotheses above suggested, it may be said that the general subsidence of the Cordilleras, or possibly a rise of the sealevel, or both movements combined, has probably brought the bed-rock floors of these valleys nearer to the ocean level than they were when the process of excavation was completed. Yet these troughs remain, in most instances, so high and their grades are so steep, as compared with others which have not become occluded, that we can not regard any hypothesis dependent on a change of grade as in itself sufficient to account for the facts. As for the second suggestion, it may again be said that it demands a complicated series of movements in the way of warping. It will hereafter be noted that such local movements due to isostacy have probably taken place, and that their effect has been to bring the bottoms of many of the valleys to a lower level than they occupied when they were in process of excavation; but these movements are a consequence of the infilling and not the cause of that process. 'Though they helped to extend the work after it was otherwise 


\section{N. S. SHALER-BROAD VALLEYS OF THE CORDIILERAS}

begun, they could not have instituted the deposition. We have now to consider the third of these possible sources of the change in conditions, as we shall find it provides a more adequate explanation than the others.

As is well known, in a normal river valley the primary agents of erosion deliver to the streams no more broken-up rock than can be conveyed by the torrents to the lower ground and sent away in solution, in suspension, or by working along on the bottom of the rivers. On the substantial completion of this transportative process the access of the. eroding waters to the bed rocks depends. In so far as the eroded material halts in its downward course, the work of erosion is lessened or arrested. In almost all valleys there are local and temporary stoppages of the debris, each of which diminishes the cutting action of the streams, but these halts in the downward course of the waste commonly are not long enduring, nor do they more than qualify and lessen the erosive work. If, however, from any cause, the amount of debris sent from the heights to the vales is greatly increased or the capacity of the river to bear it away is lessened, then the valley receives more detritus than can be borne away. It is, indeed, evident that in most river valleys, as distinguished from the channels of torrents, the amount of addition of detritus required to effect the change from degradation to aggradation is but small, for rivers normally are so adjusted that with the existing slopes they are able to do no more than keep their channels clear. If they cut down more rapidly than the summits descend, the slopes steepen and the quantity of debris is increased; if by excess in the supply of debris they cut more slowly, then the divides become lowered more rapidly than the stream beds, the declivities of the torrents are thereby lessened, and the delivery of detritus to the center of the valley goes forward with less rapidity. The question now before us is as to the ways in which this delicately adjusted state of a normal river may be so interfered with that it can no longer keep its way free.

The most immediate cause of clogging of a valley is to be found in the sudden importation of waste by other than torrent action. Thus glaciers or landslides may sweep detritus from the high country and bring about the embarrassment of drainage which is noted in the New England district and elsewhere. Again, showers of volcanic ash or more locally lava flows may fill the trough to a great depth. In the field we are considering glacial action has had no significant part in the accumulation of debris in the valleys except it may be in certain limited fields, as in central Colorado. On the other hand, the outbreaks of volcanic materials have undoubtedly done much in the way of accumulating materials which the streams were unable to remove. Where the igneous matter is in the form of lava the blocking of the valley may be so com- 
plete that the stream is forced into other channels. When the ejections are as ash the embarrassment of the drainage may be more extended and nearly as complete, for the reason that the dust, though spread over a wide area, is likely to be rapidly swept away to the low ground by the rain in such quantities that when cemented in the form of tuff the rivers can not bear it away. Where a region is the seat of extensive and longcontinued volcanic activity the original topography may become entirely hidden, as is the case in the great area of the Columbia River ash and lava fields, so that a new drainage system has to be developed.

Although in certain parts of the Cordilleran district volcanic ejections of ash or lava may have had a considerable share in forming the accumulations of the ordinary broad valleys, the evidence goes to show that they have not been the principal agent in this work. The fact that the ash deposits at Alder gulch lie in a channel cut through the slopes by a mountain torrent, and that they do not extend under the ordinary detritus of those slopes, indicates that the only accumulation of fragmentary volcanic matter of which $I$ have been able to trace the history came too late to have had any decided effect on the filling process. Moreover, very many sections, though none of them except those near Butte are of any great depth, go to show that the mass of the detrital slopes are of ordinary water-worn detritus. We may therefore consider volcanic waste as an element other than controlling in the process of deposition, and we are forced to seek the principal factor in changes in the quantity and distribution of rainfall.

So far as I have been able to find the normal mountain valleys of the world, those in which the streams which are still excavating their beds appear to be generally limited to those areas in which the rainfall is considerable and rather uniformly distributed, while the broad type, such as we are considering, is common in regions where the precipitation is scanty and irregular, where it takes on the character common in partly arid countries of torrential rains so local and violent as to receive the name of "cloud-bursts." There are many reasons why the difference in the quantity and order of the precipitation should produce a wide diversity in the amount of debris brought down by mountain torrents into a valley. As this matter has not, so far as I have learned, been set forth, I shall give it a somewhat extended presentation.

First let us note that the degradation of a mountainous country is likely to be hindered by a thick coating of vegetation, for such a covering tends to prevent the access of frost. Moreover, the joints and other interstices of the rocks are kept continually full of water, and thus in part protect it from the access of air, while in arid conditions they are filled by the occasional rains, and as the water-table sinks, as it may do 
to the extent of a hundred feet or more, the air is drawn down after it. .The most important effect of the coating of vegetation is in protecting the surface from temporary torrents. An ordinarily firm mat of roots, even those of the grasses, will usually defend the earth from the heariest streams that flow over it during the brief period when it is called on to withstand such an attack, while if not thus protected the earth would be excavated to the depth of several feet; furthermore, even where by chance a torrential rain manages to sweep a part of the protecting plants away, their debris is pretty certain to so far embarrass the work of the torrent that its load of detritus is likely to be in large part arrested on the way to the main river. It is, indeed, safe to say that the erosive effect of a given amount of water descending a torrent-making slope diminishes in a very rapid ratio with the increase in the thickness of the mat of vegetation. A virgin forest of the Appalachian ty pe will, if its bed be fairly dry, detain a rainfall of as much as 3 inches falling in, say, one hour, and distribute the discharge over a day or more. Even the precipitation of the heaviest "cloud-burst" of the Cordilleras would be so far hindered in its downward movement that it would have little destructive effect.

Where, as in nearly all parts of our Cordilleras, local rainfalls not infrequently occur to an amount of several inches an hour the scanty vegetation that prevails in that area is incompetent, in any large measure, to restrain erosion. The result is that a sheet of water sweeps down the steeps with such volume and speed that the loose material up to fragments a foot or more in diameter are swept into the torrent channels or, if the discharge be into a broad valley, far out on its slopes. I have never had an opportunity to observe a good example of these interesting floods, but from the accounts I have had of them from trustworthy observers and from an examination of their effects I am satisfied that the amount of debris which is by their action discharged into the broad valleys is very great, and that the process is one that has hardly any likeness in regions of considerable and uniform rainfall.

Although the contribution of debris to the detrital slopes of the valleys, as may be readily seen in the field, comes to them in part directly from the action of torrential rains, carrying the debris out onto their surfaces, the larger portion of the eroded material is delivered by way of the permanent torrent channels and disposed as detrital fans at their mouths. If the points of discharge of these torrents were permanently fixed, the debris thus brought into the main valleys would be heaped into a series of these fans, while in the spaces between the gulches there would be only the waste brought down from the steeps that face the valley-debris which did not pass through the torrent channels. In 
fact, however, there is no such localized arrangement traceable. The detrital slopes have a remarkably even and continuous upper limit next the erosion faces, though they are commonly higher between the torrent mouths than elsewhere. This peculiarity is probably due to the fact that the positions of the mouths of the torrents are evidently liable to frequent changes, and that in the geologic periods during which these valley deposits have been accumulating this constant alteration would tend to effect an even distribution of the material brought down by the tributary streams.

The changes in the positions of the torrents are brought about in several different ways. 'Thus the process known as the robbing of one drainage basin by another is of very frequent occurrence in this region. Instances of it may be noted in almost any area that is attentively examined. Again, where, as in most mountainous districts, the strata have varied inclinations, the channels are led by the attitudes of the beds to change their positions as they work downward. Yet, further, the heaping up of debris in the center of a detrital fan tends to divert the streams to the margins of the steep delta, so that the range of the deposition is greatly extended. Moreover, the various tiltings to which the several areas have been subjected have doubtless served to change the course of these streams and the accumulation of their discharge. All these influences and probably others not yet discovered have served to bring about in course of time a tolerably even distribution of the materials brought down by the steep graded streams into the broad valleys.

Turning now to the main rivers which drain the valleys, let us consider what are the conditions of their action during the period when the greater part of the precipitation is in torrential rains. As it is characteristic of these rains to be very local, they often being limited to a few square miles of area, the amount of water they send into the rivers is too small to have much effect upon their volume or speed. Moreover, for the reason that the detrital materials of the valley are very open in structure they quickly absorb much of the flood, so that the reinforcement of the main stream is apt to be slight, while the water which comes to it is heavily charged with debris too coarse for the slower movement to bear away. The result of these conditions is that the streams in the center of the broad valleys tend to aggrade their channels, while in normal rivers the contributions of detritus brought to them by torrents come so slowly to their beds that the materials have a chance to decay and break up to a state where they are readily transported in solution, in suspension, or by being rolled along the bottoms. In these abnormal streams the excessive discharge from the torrents cannot be thus removed. As 
soon as a river ceases to cut downward and begins to aggrade it passes a critical point in its history and begins at once rapidly to lose its capacity to deal with the obstructive matter that comes to it. In proportion as the bed rises, the rate of flow must diminish, with a consequent and rapid loss of capacity to erode or carry debris.

The degree of the obstruction of the channel of the main stream due to the causes above mentioned depends on the distance of the point where its tributaries emerge from the mountains into its valley. Where, as in the case of Alder creek, Madison county, Montana, the detrital fan is about 4 miles in length, the greater part of the coarse debris is in the existing regimen of the stream deposited on the slope, but little of it entering Ruby river. In the lower part of its course the creek has a fall of little less than 20 feet to the mile, and in its original condition it found a devious and much obstructed way through a dense growth of shrubby vegetation. It happens, however, that whenever a valley is narrow, as it commonly is at the point where its stream cuts through a range of mountains, the detrital fans are steep, and the discharge of waste into the channel goes on rapidly. In this case the effect is to increase the rate of shoaling of the river bed, so that by the consequent diminution of the current a deposit of coarse detritus is laid down in the stream bed. Occasionally above these narrowed parts of the troughs there occur considerable areas of swampy land.

The obstruction of the drainage of the broad valleys is in some measure effected by the action of the wind in bearing dust from the more arid parts of the area' to the banks of the streams. It may be here briefly noted that this dust is impounded in the rank vegetation which is commonly developed as a selvage along the banks of the water-courses, forming a characteristic loose deposit. In the course of the frequent changes in the position of the channel this wind-borne waste is apt to be washed away, but it adds to the load of the overburdened stream and diminishes the efficiency of its work. On the detrital fans this accumulation of dust, partly by its direct obstructive effect and partly through its influence in promoting a dense growth of vegetation, tends to force the torrents into continued wanderings and thus to a wide distribution of the debris which they lay down.

On the basis above laid down we are led to construct a general hypothesis as to the condition which brought about the present aspect of the Cordilleran broad valleys. First we have to suppose an ancient long continued period of normal river action in which deep valleys of the Alpine type were formed. Then a period, or rather a succession of periods, of aridity in which the rivers were brought into the abnormal state where they could not remove the debris which the torrents conveyed 
to them. In this state the channels proceeded to fill and the detrital slopes to climb higher upon the sides of the mountains. Wherever by the erosive process a part of the lower slopes of the ranges came to have a gentle declivity the accumulating debris would mantle it over; where outlying peaks became islanded in the detrital deposits they continued to wear down until, if their original height were not too great, the slowly rising surface would overtop them.

It is evident from the sections seen at Butte and elsewhere that the mantle of detritus lying on the bed rock tends to preserve that rock from further decay. This is brought about by a simple process, one commonly occurring in all gravels made up of rocks that afford soluble material, such as iron or lime. This dissolved matter finds its way down upon the bed rock, and there cements the lower part of the detritus into a hard mass which is impervious to water. Whenever we attain this contact of the detritus with the crystalline rocks we find this protecting layer, with the result that decay does not seem readily to occur beneath it. It is otherwise with the materials of the valley deposits between the upper section, which is prevailingly very dry, and the cemented layer. In this zone the process of decomposition appears to be tolerably rapid, as is shown by the considerable discharge in the seeping springs that appear along the streams when the water is commonly much charged with lime and iron.

In the manner above noted we can perhaps account for the peculiar shoulders of the bed-rock valleys which, apparently in a somewhat general way, extend from the margin of the steep gorges to the foot of the exposed portion of the mountain ranges. The process of occlusion of the narrow steep-sided central part of the valley probably would go forward with such rapidity that the exposed cliffs would not be worn down so that they could become covered. As the deposit rose higher in the trough it would encounter gradual slopes on which the detrital coating would, even where thin, preserve the bed rocks from further decay. It is evident that with a slope of about 150 feet in the mile the materials of the benches are commonly able to keep their place so that any declivities of less inclination would be protected. In this way, as the erosion forced back the faces of the mountains the valley would be widened, the gain representing the advance in the decay of the mountain fronts down to the level where the detrital accumulations began to protect the rocks.

This view as to the way in which the broad valleys widen may help us to understand the peculiarly straight walls which the ranges that border them present. As before noted, the generally rectilinear aspect of these mountain fronts demands explanation. It is, indeed, as striking an element as is the width of those vales. The feature may be due, 
at least in part, to conditions which determine the advance of the talus slopes. Whenever they come against steep rock faces, where the process of erosion is likely to be rapid, the talus climbs to a steeper angle because of the larger supply of detritus. It thus tends the sooner to mask the elevation. Where, on the other hand, the rock slopes are gentle, the talus grows less rapidly because of the insufficient supply of debris, and therefore does not advance so rapidly on the barrier. Although the general aspect of these slopes when seen from the distance is that of uniformity as regards their upper margin, closer inspection shows that they vary considerably in that regard, the range in some of the valleys being near a thousand feet of elevation. So far as observed, they are generally highest against the more precipitous faces of the mountains at whose feet they lie.

The measure of the development of the broad valleys will on careful study probably be found to differ much in the several areas of the Cordilleras of this country. There appears on rough inspection to be a distinct increase in the amount of the aggradation as we go southward from the Canadian line, and on the whole a decrease in the amount of it as the region is nearer to the Pacific coast and to the Mississippi valley. In general, the ratio of the infilling seems to be inversely proportionate to the amount of the rainfall that now occurs in that mountain system. In the Montana district the appearance of the taluses, their occasionally eroded surfaces, and what can be seen of the action of torrential rains suggests that the accumulation of detritus is not going on at present with any great speed, if, indeed, it is not replaced by erosion, while in Arizona the amount of debris at present brought down by the flood waters is most noteworthy. Thus in the valley of the Williams fork of the Colorado a flood caused by torrential rains has been observed to cover an area of many thousand acres with debris to the depth of 20 feet or more. On the eastern face of the Cordilleran mountain system in Colorado the aspect of the taluses suggests that they are generally in process of destruction. The same condition is indicated in the belt of country near the Pacific ocean.

The most complete effacement of the original valleys appears to have taken place in the region known as the Mojave desert. Here the detrital slopes have risen to near the tops of the ranges. The most extensive benches and perhaps the broadest of the valleys I have examined are in the basin of Hassayampa river, near Congress junction, Arizona. The least development of the infilling process, still considerable, is the valleys of northern Montana. It has been before noted that along the Pacific coast the amount of debris impounded in the valleys is relatively small.

In the region of the Great basin the phenomena of infilling are more 
or less obscured by lake deposits. Such lacustrine conditions, though they may be due to other causes, are likely to be brought about in any of these valleys by the irregular subsidence of their floors under the influence of the loads that are brought on them.

If we were here considering in a general way the effect of any excessive discharge of sediments into a river system in the manner in which it has taken place in the Cordilleran district, we might much extend the subject-matter of this paper. It would be interesting to note that the result of the filling of valleys is to change the effective base line of erosion of all the streams that lead down to them, and that the natural completion of the process is the development of an extensive broad upland with shallow valleys where there was originally a strong mountain topography. In other words, a kind of summit leveling action is then taking the place of the usual baseleveling process. To this condition a large part of the Cordilleran system within the United States is obviously tending.

Although in the absence of close study of the problem these impressions concerning the increase or decrease of the talus slopes can not be considered as more than foundations for inquiry, it may be well to note on what they depend. Where the slopes are continuous and of even surface, with no new-made channels, particularly when they gradually steepen up to the walls of the mountain, there is reason to believe that, while they are subjected to some interstitial decay, they are not subjected to much surface erosion. Where, how ever, the crest line is sharply irregular, and especially where extensive areas of gently sloping bed rock are exposed, it is a legitimate working hy pothesis that the upper edge of the talus has been so far eroded that it has lost a part of its height. Here and there in northern Montana low foothills occur which can not be accounted for by the structure of the rocks, but seem to have been produced by the lessening in the height of the taluses and the consequent dissection of the newly exposed bed rock. A proper determination of this question as to the growth or shrinkage of the taluses under existing conditions will be difficult to make.

While the present average state of growth or decay of the deposits in the broad valleys is not determinable, there appears to be good evidence that there has been at least one period of the past, and that near to our day, when for a time these beds were in process of rapid wasting. This is shown by the general occurrence of many wide and often still deep passages through the slopes where the torrents cross them. These excavations occur in all the broad valleys I have had a chance to examine. It is clear that they have not been formed by the torrents in their existing volume, for they have no fresh scarps, and those of recent date 


\section{N. S. SHALER-BROAD VALIEYS OF THE CORDILLERAS}

have usually gentle and completely adjusted slopes. Moreover, in all the many instances $I$ have inspected the torrent is now engaged in constructing a detrital fan within the valley which a while ago it was excavating. Not only are there valleys where the permanent streams intersect the benches, but at many points we find such valleys where there is at present no effective stream at work at any season. These might be taken as the result of torrential rains but for the fact that they all appear to be very ancient. Moreover, they seem to have been excavated by moderate, continuously acting streams and not by a cataclysm. A part of the evidence on this point is afforded by the fact that these ancient wadys are in all the regions abounding in alluvial gold, the seat of local placers, the metal being in winnable quantity because it is a concentration from the general mass of the talus deposits. The distribution of this gold in the wady, where it occurs in benches of rearranged gravel, shows that these now dry valleys have had an ordinary stream history.

The duration of this last period of more abundant rainfall must have been considerable, for the erosive work done on the taluses was evidently great. The gorges formed by the main torrents were, in many instances, a mile or more wide and from 1 to 300 feet in depth, though they have since been to a great extent refilled during the later now existing stage of accumulation. They generally remain very distinct features. At the present rate of growth of the detrital fans, it would require a geologically long time for the replacement of the debris which was removed from these cross-valleys. It appears likely that this channeling of the valley deposits which is shown where the torrents cross the slopes continued down to the centers of the troughs of the rivers, so that the drainage flowed in canyon-like gorges of considerable depth. Although these canyons cut in the debris are in process of refilling and are sometimes almost occluded, they can often be traced by the slight escarpments which show where their margins lay. Such sections as have been disclosed of the beds which have been laid down in these ancient waterways show relatively fine, worn debris differing in texture from that which makes up the slopes on either side of the river.

So far as the evidence goes, it is to the effect that this period of increased rainfall and consequent reinstitution of erosion in part coincided with the last development of glaciers in this region. It appears to have continued after the retreat of the local ice-streams from the valleys, as is shown by the fact that the morainal fields are incised by channels which are no longer the seat of cutting streams. It may also have somewhat preceded the development of those ice-fields, as is occasionally shown by the semblance of such dead valleys partly covered by drift materials. It is not easy to make observations of value as to this ques- 
tion, for the reason that at only a few points have $I$ been able to find morainal deposits lying upon the talus slopes in positions where the history of channels due to increased rainfall can be traced. The best of those lie on the west side of the Jefferson river, between Whitehall and Twin Bridges, Montana. Although the evidence is not as complete as might be desired, it seems to be fairly conclusive as to an increased precipitation before and after the Glacial period, though the amount thereof is not determinable.

The relation of the glacial deposits to the materials which fill the broad valleys clearly establishes the fact that the valleys were in sub. stantially their present state before the advent of the ice-streams. The changes which have taken place in post-Glacial time have been very slight. Certainly not the hundredth part, and probably not the thousandth part, of the detritus borne in from the hills has been laid down since the close of that humid period in which the principal work of excavation was done. If, then, we allow a duration of 100,000 years to have elapsed since the departure of the glaciers from the valleys and the reestablishment of the arid conditions as they now exist-in my opinion, far too short a time-and suppose that the process of infilling has of late been of average rapidity, we are led to conjecture that some million years have elapsed since the work began. As to the time when the change from normal to abnormal stream-work occurred, we have as yet no trustworthy evidence, nor do we know that it took place coincidently in all parts of the region. While by no means conclusive, the evidence in general points to the conclusion that the excavation of these vast basins, as well as the process of their refilling, has been substantially accomplished in the periods since the Cretaceous.

It may be incidentally noted that the effect of the temporary humid climate during the Glacial episode appears to be marked in the conditions of the vegetation of this region. In certain regards the plants, particularly the trees, exhibit a lack of adjustment to the state of the soil such as they now have to meet. The natural way by which plants adapt themselves to arid conditions is by sending tap roots downward to the water level, as in the case of the "beach grass," Carex arenaria, which often sends down such roots to the depth of from 10 to 20 feet below the surface. Other instances may be found in the many tap-root trees. It is a noticeable fact these accommodations to arid conditions appear to be generally lacking in the Cordilleran vegetation. It may well be supposed that during the last humid epoch, which may be presumably reckoned as equivalent to the latest Glacial period of the northern hemisphere, this region lost the species which had previously been adapted to dry conditions, and that since the aridity was reestablished 
there has not been sufficient time for the differentiation of new species adapted to the environment.

If the presumption just above noted as to the age of the broad valleys be affirmed it will serve to throw much light on the duration of the Cenozoic age. The tendency of geologists has, in my opinion, been to under-reckon this section of time. It is generally computed, from the thickness of the sediments and other evidences, as far less long than the Paleozoic or even the Mesozoic ages. I have elsewhere* undertaken to show that the geological results of that age must have required many million years for their development. If the further study of the Cordilleran valleys bear out the preliminary judgment above set forth we shall have yet stronger reasons for revising our conceptions concerning the duration of the last great geologic age.

\section{EFfects of Deposition}

There are certain secondary effects arising from the infilling of the broad valleys which deserve attention. In the first place we note that the transfer of a vast body of debris from the mountain ranges to the center of the troughs must naturally have led to the subsidence of the bases on which the weight was imposed and a corresponding rise in the areas whence the materials were deported. If we reckon the average depth of the detrital materials laid down in these valleys at 3,000 feet, then the consequent subsidence should be some large portion of that amount. In all probability the deposits of the greater vales much exceed the amount here assumed. In proportion to the subsidence, but probably somewhat less in amount, there would be a rise in the areas of erosion-that is, the bordering mountain ranges. The axis or neutral point of this movement would naturally lie near the junction of the valley deposits with the high country. Its position would be unstable, as it would tend to become extended farther and farther from the central line of the depression as those deposits encroached upon the steeps. Assuming that this effect arising from the isostatic action occurredthat it in some measure occurred is almost a necessary suppositionthere are several interesting consequences that require consideration. In the first place we shall be able thereby to account for the great depth of these valleys without having to suppose that continuously inclined drainage channels cut in the bed rocks still exist. There is, indeed, no reason why the floors of the troughs may not have been borne down for

* Report on the Geology of the Cape Cod District. Ann. Rept. Director U. S. Geol. Survey, $1896-97$, p. 588. 
thousands of feet below the level at which the waters which excavated them were of old discharged into the sea or into the greater rivers.

The hypothesis of isostatic movement may serve in part, at least, to explain the often wall-like character of the mountains that face these valleys. As has already been noted, this aspect of these vales is so striking that it demands an explanation. If we assume a continued settling of the floors of the valleys, accompanied by an upward movement of the neighboring ridges, we may well imagine that we would have much faulting about the changing axial line. In other words, each. of these valleys would be the seats of more or less considerable step faults, the whole forming a complicated "graben "like basin. There are not lacking instances of a like structure in basins which have been deeply filled with sediments. Thus on the eastern coast of the United States we have in the Richmond basin what seems a similar instance of a valley step faulted under a heavy burden.* The Narragansett basin, in Rhode Island and Massachusetts, is a similar instance of a basin that appears to have been downborne by the weight of sediments imposed upon its floor. It is, indeed, likely that this downbending of loaded troughs is a common feature.

It is to be noted that in the filled basins of the James river and the Narragansett districts of the Atlantic coast, the former of 'Triassic and the latter of Carboniferous time, we have the same abundant developments of arkose deposits that we find in the broad valleys of the Cordilleras. These facts suggest the hypothesis that the process of occlusion of valleys in the manner indicated in the troughs we are considering may be sufficiently common to be regarded as of general importance. The fact that in the eastern basins there are occasional coalbeds in certain parts of the section may mean no more than the temporary occurrence of humid epochs, such as that which has just passed away in the western part of the country.

It is evident that in case it should be found that deposits of the broad valleys have in a way determined the development of the orogenic movements of the region in which they lie, very interesting light would thereby be thrown on the history of the mountain-building in the Cordilleran and other regions of like conditions. At present, however, the value of the hypothesis is not proved, so that it does not merit further discussion.

There is a peculiar feature in the recent volcanic activity of the Rocky mountains of which we may possibly find an explanation through the action of the valley deposits. 'This is the occurrence of eruptions at various points at a time when the sites of these outbreaks were remote

*See Ann. Rept. Director U. S. Geol. Survey, 1897-'98, p. 401. 
from the rea. It is a well known fact that no such explosions have been noted in the historic period at a greater distance than about 250 miles from the ocean; yet many of the eruptions in the Cordilleran district which have recently occurred are several times as far from the coast. The only apparent reason for the limitation of volcanoes to the seafloors or to the margins of the lands is that the development of the tension, principally of steam, that brings about eruptions is caused by the rise of temperature in rocks due to the non-conducting effect of strata which have been laid down on the sea-floors. Accepting this explanation, it appears not unlikely that the outbreaks which have taken place in the region we are considering may have been caused by the great deposits which have been accumulated over the wide area of the broad valleys. It is true that the rise in temperature would not in general exceed one degree Fahrenheit for each 50 feet of beds laid down, and that a depth of 10,000 feet would probably effect no more increase in the basement of the section than 200 degrees Fahrenheit; yet such a gain in heat might at a depth in the crust when the tensions were already near the critical part of an explosion be efficient in bringing it about. Moreover, as is indicated by the hot springs in this region, there are evidently many large areas where the temperatures at no great depth are high, a condition due perhaps to ancient volcanic pipes or great dikes or sheets of lava which are still very hot. In case these were deeply covered with sediments the rate of rise of the isogeothermal planes would be much more rapid than would ordinary conditions, and an explosive tension would be more readily attained.

It may be asked why the eruptions from the interior districts of the Cordilleras have apparently now ceased, while they were evidently of frequent occurrence in the later Tertiary and perhaps in the early Cretaceous periods. The answer may be found in the fact that the process of deposition in the broad valleys was evidently arrested during the humid period, of which the local glaciation of the region was an incident, and that for some time and in a considerable measure it was replaced by erosion. The further deposition now going on has evidently not been sufficient to restore to these valleys what was removed during that time of more abundant rainfall. The only sufficient verification of the hypothesis that these inland volcanoes owed their origin to local deposition will be had in an examination of other countries where like deeply filled broad valleys exist. I have essayed this through records, but these are so imperfect that they have not proved serviceable.

Some of the apparently modern eruptions of the Cordilleran region appear to negative this hypothesis, as, for instance, those which have occurred in the Colorado canyon. I have not been able to examine 
these seeming exceptions sufficiently to determine whether they render the view above suggested untenable.

\section{Exceptional VaLLeys}

It has been incidentally noted that in certain parts of the Cordilleras valleys occur which clearly indicate a different adjustment of the conditions of erosion from those long prevailing in the characteristic refilled broad valleys. So far as I have been able to examine these exceptions they appear to be accounted for by peculiarities of situation or by exceptional movements of the underlying earth. The diminution in the amount of infilling after the periods of great erosion on the Pacific coast is explicable from the fact that these valleys near the ocean have never had their streams so far reduced in flow as to bring about any large amount of aggradation. There are, however, two districts where the process of infilling is absent or noticeably less than might be expected if the hypotheses here advanced to account for the broad valleys were true. These are the sections traversed by the canyon of the Colorado and that on the eastern face of the Cordilleras from central New Mexico to the Canadian line. The reasons for these exceptions may perhaps be found in certain geographical accidents that are noted below.

As for the Colorado river, it is well known that, while it traverses one of the most arid portions of the Cordilleran region, it derives its water from the snows of the high mountains on the eastern side of the Rocky mountains, where for ages the precipitation must have been considerable. Cutting as it does through a region which clearly has long been characterized by a very scanty rainfall and where there has been an extensive upward movement of the rocks, it has formed and kept open a deep valley. Although the sides of this trench have been much intersected by tributaries, the amount of debris which they have brought down has not been greater than the vigorous river has been able to take away. The result is a valley in which the stream has been able in the main to retain its place on the bed rock. As these conditions of the Colorado river are rather exceptional, and as they appear to account for the lack of aggradation we find there, we may therefore reasonably conclude that the features of this valley do not militate against the hypothesis.

As elsewhere noted, the eastern face of the Cordilleran district affords evidence that goes to show a recent augmentation of rainfall beyond any increase that is indicated in the central region. This is most evident in the southern portion of this district, as in southern Colorado and New Mexico. In that area we have fairly broad valleys which often exhibit the form of the bed rock cut, which has been described as existing be- 
neath the alluvial deposits of the Silver Bow river at Butte, Montana. They have wide bottoms, declining gently from the base of the bordering ranges to near the center of the trough, and then a sharp canyonlike gorge descending to the ancient level of the stream. A fair though small example of these structures is seen in canyon Diablo, on the Santa Fé railway. The simplest explanation of these valleys would be to suppose that after they were broadened out in adjustment to one baselevel of erosion the region in which they lie had been elevated or tilted so as to increase the cutting power of the streams. There are, however, several reasons why this view is not satisfactory. In the first place, as just above noted, the shape of these vales is identical with what we find in those of the more arid district which has been filled with debris. In the second place, these troughs lie too far above the sea to have had the regimen of their streams altered by any such change in its level as has recently occurred. The central canyon is by no means continuous down to the coast line, as should be the case if its existence was due to recently augmented erosion brought about by a change of level. As for the suggestion that there has been an increase of erosion due to tilting, evidence to show such movement is quite lacking; there is no such contrast in the conditions of streams flowing in diverse directions as normally, indeed necessarily, marks a drainage system which has been thus perturbed.

Any alteration of the slopes of this region sufficient to have produced the reexcavation of these valleys would be indicated by a general disturbance of drainage such as has evidently not occurred.

Along the eastern face of the Rocky mountains there are several features which deserve notice, for the reason that they appear to throw some doubt upon the hypothesis that the long continuance of an arid climate will account for the refilling of valleys excavated during humid periods. First of these is the deep canyon valley of the upper Arkansas river. This gorge is on some accounts more puzzling than that of the Colorado, for the rea on that while the upper part of the trough is of normal width and has been extensively refilled, the canyon section is relatively narrower than almost any other formed by the Cordilleran streams. I have been unable to determine the reason for this peculiar feature. It may be due to some recent uplifting of the section in which the canyon lies, or possibly, though not probably, to a difference in the rate of decay of the rock in the different parts of the valley. It should be noted that this stream, like the Colorado, is fed from the melting snows of a high country where the rainfall is and doubtless has long been considerable. The fact that the valley above the gorge was the seat of extensive glaciation during the last ice epoch clearly indicates that the annual precipitation has recently been much greater than it is at present. 
The frequent occurrence of foothills at the base of the main ranges, both on the eastern face and in the valleys of this section of the Cordilleras, is noteworthy. Here, as elsewhere, these low ridges have noticeably accordant heights; they are, moreover, much less dissected than are the mountain at whose feet they lie. Wherever these foothills are well developed the talus slopes are inconspicuous or wanting. If the view previously expressed, to the effect that foothills of this type result from the exposure of a portion of the gently sloping bed rock of a valley which took its first shape while the process of refilling was going on, then the process of baring and dissecting must have been a concomitant of an increased rainfall which has served to destroy the ancient talus slopes or benches. In other words, we have to suppose that an arid period, during which extensive taluses were built, was followed by a humid period, in which they were to a great extent swept away.

\section{Possible Cause of increased Ratnfall in eastern Cordilleras}

At first sight it may seem that the last Glacial period, with its increased precipitation, could sufficiently account for the augmented rainfall which the features just above noted appear to demand for their explanation; but it is probable that the increase in erosive action in this eastern section of the Cordilleras is much more ancient than the ice-time. Although the dissection of the upper part of the rock slope is often of the canyon type, the incisions are deep and apparently must have required far more time than elapsed since the beginning of that humid period. In view of the facts, I have been led to a hypothesis as to the cause of this ancient temporary increase of rainfall and of the aridity which preceded it. This view I shall now set forth.

It is eminently probable that the source of the larger part of the rainfall that comes to the drainage basin of the Mississippi valley, including the eastern portion of the Cordilleras, is to be found in the basin of the gulf of Mexico and the Caribbean sea. Depending on the evaporation from this basin as the source of precipitation, we may reasonably suppose that any great variations in the area of these seas would be attended by changes of rainfall which might, if the alterations were great enough, range through a wide scale. Although we can not as yet clearly trace the alterations of the Caribbean group of seas in the later geological periods, we know enough to be sure that these have been great. Developing mainly about the eastern and western mountain systems, this continent has, since the Paleozoic age, had a broad, low interval between the Appalachian and Cordilleran high ground-a region so little elevated above the average level of the ocean that it has in many alternations been dry land and shallow sea. Still further, in southern Louisiana, where 
there is at present an annual rainfall of about 100 inches, there exist very extensive deposits of rock-salt beds, which indicate an arid climate, with a precipitation of probably less than 10 inches, and a very dry air. Although the age of these beds is not determined, it is, on the whole, likely that they are of Mesozoic age. These facts, while they do not suffice to correlate any particular climatal condition in the eastern face of the Rocky mountains with a particular accident in the form of the gulf of Mexico, clearly indicate the existence of actions sufficient to account for a wide range in the precipitation in that part of the Cordilleras. If it were necessary further to show that the eastern border of the Cordilleras had been subjected to one or more humid periods before the last Glacial epoch, the evidence could be adduced from the conditions of the valleys of the rivers which drain from that district toward the Mississippi. These valleys generally indicate the existence of a greater flow, and this at a time anterior to the accumulation of the glacial drift.

\section{ConcLusions}

The foregoing considerations lead to the conclusion that the valleys of the eastern face of the Cordilleras were in most, if not ail, cases greatly affected by a long-continued arid climate, which at some time probably in the Tertiaries was interrupted by one or more continuously humid periods, with a return in the present epoch to dry conditions. During the Tertiary periods, when aridity prevailed, the originally deep and rather narrow valleys probably were filled with debris and widened under the conditions of a constantly rising baselevel formed by the thickening deposit, the conditions of this action being the same as those traced in the interior valleys of the Cordilleran field. At the same time like accumulations of detritus formed on the eastern border of the mountains-that which faces the great plains. In later times there came a greater measure of rainfall, and, as a consequence, the removal of a large part of the filling of these eastern valleys, as well as the greater portion of the talus deposits on that border of the mountains. In this period the upper part of the bed-rock slopes of the valleys were bared and worn into foothills.

At present the conditions of the eastern section of the Cordilleras indicate a recent return to the arid climate which has for ages been normal in that area. The taluses are evidently again in process of increase, vigorous erosion being limited to the higher levels, where the steepness of the torrent beds enable their scanty waters to sweep along the debris which comes to their beds. Unless the gulf of Mexico should again be brought over a considerable part of the southern lowlands, there seems to be no reason to expect that there will be any increase of rainfall in this area. 


\section{Geological Society of America Bulletin}

\section{Broad valleys of the Cordilleras}

N. S. SHALER

Geological Society of America Bulletin 1901;12, no.

$1 ; 271-300$

doi: 10.1130/GSAB-12-271

Email alerting services

click

www.gsapubs.org/cgi/alerts to receive free e-mail alerts when new articles cite this article

Subscribe

click

www.gsapubs.org/subscriptio ns/ to subscribe to Geological Society of America Bulletin

Permission request

click

http://www.geosociety.org/pub s/copyrt.htm\#gsa to contact GSA

(C) 1901 Geological Society of America

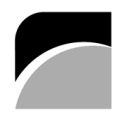

THE GEOLOGICAL SOCIETY OF AMERICA 
Copyright not claimed on content prepared wholly by U.S. government employees within scope of their employment. Individual scientists are hereby granted permission, without fees or further requests to GSA, to use a single figure, a single table, and/or a brief paragraph of text in subsequent works and to make unlimited copies of items in GSA's journals for noncommercial use in classrooms to further education and science. This file may not be posted to any Web site, but authors may post the abstracts only of their articles on their own or their organization's Web site providing the posting includes a reference to the article's full citation. GSA provides this and other forums for the presentation of diverse opinions and positions by scientists worldwide, regardless of their race, citizenship, gender, religion, or political viewpoint. Opinions presented in this publication do not reflect official positions of the Society.

Notes

(C) 1901 Geological Society of America

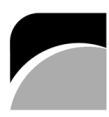

THE GEOLOGICAL SOCIETY OF AMERICA 